\title{
PENINGKATAN EKONOMI DAERAH MELALUI PELATIHAN UKIR LAMPUNG DAN PEMBUATAN E-COMMERCE UNTUK PENGRAJIN UKIR DAN SMK UKIR DI BANDAR LAMPUNG
}

\author{
TM. Zaini, Anggalia Wibasuri, Ronny Nazar ${ }^{1}$ \\ Institute Informatics And Business Darmajaya \\ Jalan Zainal Abidin Pagar Alam 35142 \\ Telp. 0721 - 787214 Fax. $0721-700261$ \\ website : http://darmajaya.ac.id \\ e-mail : tmzaini@ymail.com
}

\begin{abstract}
Lampung merupakan Provinsi yang terletak di pintu gerbang Pulau Sumatera memiliki dua unsure masyarakat adat yaitu Papadun dan Saibatin yang biasa disebut Ulun Lampung. Seiring dengan visi dan misi Provinsi Lampung untuk terus melestarikan adat (budaya) nya termasuk seni Ukir Lampung, maka tujuan yang ingin dicapai dalam pelaksanaan pelatihan ukir lampung ini untuk melestarikan dan mengembangkan seni ukir lampung melalui pengrajin di daerah Langkapura Kemiling Bandar Lampung dan SMK Ukir seperti SMK Negeri 5 Sukabumi Bandar Lampung. Keberlangsungan kerajinan ukir Lampung ini sehingga dapat meningkatnya peran kelembagaan dalam permodalan UMKM dalam pengembangan ekonomi lokal yang berdaya saing, menurunnya angka kemiskinan menjadi 20\%, meningkatnya jumlah kegiatan seni dan budaya, meningkatnya jumlah wisatawan lokal dan mancanegara dan yang berkunjung ke Provinsi Lampung untuk melihat produksi ukir Lampung dan membeli secara langsung dari tempat produksinya, berkurangnya jumlah penyandang masalah kesejahteraan sosial (PMKS), meningkatnya akses dan kualitas prasarana dan sarana perhubungan terutama untuk pendistribusian hasil kerajinan ukirs. Metode yang dipakai dalam pelaksanaan pengabdian masyarakat ini adalah persiapan, pelaksanaan pelatihan, penyajian materi melalui penugasan praktek, refleksi dan penutupan program serta sosilisasi penggunaan E-Commerce untuk pengabdian kepada masyarakat dan evaluasi kegiatan pengabdian masyarakat pada pelaksanaan pelatihan ukir kelompok pengukir baik pengrajin dan Siswa SMK Negri 5 Sukabumi Bandar Lampung.
\end{abstract}

Keywords: kerajinan ukir lampung, pelatihan, produk dan e-commerce. 


\section{PENDAHULUAN}

Pembangunan daerah terutama sector seni budaya khususnya seni ukir lampung di Provinsi Lampung merupakan rangkaian kegiatan untuk mencapai tujuan yang diinginkan yaitu masa depan yang lebih baik. Dalam rangka menetapkan tujuan pembangunan daerah secara merata di segala sector, diperlukan visi dan misi yang mengarahkan pandangan ke depan mengenai cita-cita yang disepakati bersama dan sebagai pedoman seluruh pihak yang terlibat dalam pembangunan Provinsi Lampung, baik oleh pemerintah, swasta maupun masyarakat (seluruh stakeholder) dalam menempatkan peran masing-masing dalam melestarikan dan membangun seni budaya serta peningkatan ekonomi daerah di Provinsi Lampung.

Guna menyelaraskan seluruh aspirasi, langkah strategik, energi masyarakat untuk pembangunan, dan identitas masyarakat untuk bergerak ke arah yang lebih maju, baik secara komparatif ataupun secara kompetitif, maka ditetapkanlah VISI Provinsi Lampung adalah 2010-2015 : "Terwujudnya Provinsi Lampung yang Maju, Berbudaya, Berdaya Saing dan Sejahtera". Gambaran kegiatan yang akan dilakukan dalam rangka pencapaian visi Provinsi Lampung 2010-2015, yang selanjutnya dijadikan sebagai sutu pedoman dalam penyusunan strategi yang dirumuskan dalam arah kebijakan dan program prioritas dalam mengalokasikan sumber daya daerah, maka ditetapkanlah misi Provinsi Lampung yaitu meningkatkan kualitas SDM, kesehatan dan kesejahteraan sosial masyarakat.

1. Mengoptimalkan potensi perekonomian daerah dan sumberdaya lokal serta pemberdayaan masyarakat.

2. Memelihara dan Meningkatkan infrastruktur dan pembangunan di daerah.

3. Mengoptimalkan pengelolaan sumberdaya alam dan lingkungan hidup.

4. Mewujudkan tata pemerintahan yang baik dan bertanggungjawab.

Melihat dari visi dan misi Provinsi Lampung, pemerintah dapat mencapai tujuannya dengan ditunjang kondisi masyarakat daerah itu sendiri. Jika dilihat dari sisi ekonomi kerakyatan maka digalakkan usaha kecil menengah dan ini bisa dilihat dari kerajinan terkenal diluar Provinsi Lampung.

Salah satu kerajinan yang paling perlu dilestarikan adalah seni ukir lampung. Seni Ukir Lampung merupakan salah satu jenis buah tangan nan indah dari kerajinan tradisional sekaligus ornament-ornamen adat khas Lampung. Ukiran lmapung biasanya berupa seni pajangan dan juga terdapat pada pintu rumah, atap (resplang), dan perabot rumah tangga juga yang peralatan dan perlengkapan yang biasa dikenakan pada acara adat seperti acara resepsi pernikahan dan acara tradisional lainnya.

Ukiran Lampung dibuat menggunakan peralatan tradisional dan dalam proses pembuatannya adalah hasil tangan-tangan terampil pengrajin ukir. Lama pengerjaannya tergantung pada tingkat kesulitan dan bentuk ornamen-ornamen dan bahan yang digunakan serta ukurannya dan kerumitan motifnya. Sebuah ukiran kecil seperti hiasan dinding dengan ukuran lukisan dinding dapat diselesaikan dalam waktu waktu satu minggu bahkan satu bulan atau lebih. Proses pengukiran dilakukan secara manual dengan tangan. Dibutuhkan ketekunan tinggi dan teknik tertentu mengukir agar hasil ukiran terlihat rapi dan indah. Kerajinan seni ukir ini sempat nyaris menjadi komoditi langka sebab tak banyak orang yang menggeluti ukiran lampung ini. Akan tetapi, kini seni ukir ini sudah mulai diproduksi pengrajin dengan ragam hias yang lebih variatif. Sebagai barang komoditi yang memiliki nilai ekonomis tinggi, sehuah ukiran hiasan dinding motif lampung dengan ukuran $30 \mathrm{~cm}$ x $60 \mathrm{~cm}$ bisa dihargai Rp 400.000,- hingga Rp1.000.000,-. Seiring perkembangan zaman dan kreativitas, seni ukir lampung tidak hanya diaplikasikan pada hiasan dinding dan perabot rumah tangga. Banyak cenderamata atau hiasan kreasi lainnya yang mengaplikasikan seni ukir lampung. Beberapa diantaranya adalah hiasan dinding berupa ayat kursi dengan ukiran ornament lampung, souvenir ukiran lampung tempat pena, hiasan ukir pemisah ruang dengan motif binatang atau kapal khas motif lampung, gantungan kunci, tempat tisu dan lainnya. 
Pada saat ini kerajinan ukir lampung semakin sedikit yang menggeluti. Sebab, selain pengerjaannya rumit, membutuhkan kesabaran yang tinggi untuk mengerjakannya dan agak sedikit tertinggal. Selain itu dizaman sekarang ini banyak pengrajin yang tidak memiliki keterampilan dalam mengukir dan memasarkannya padahal SMK untuk bidang ukir ini sudah ada.

Hal ini jelas bahwa di daerah Provinsi Lampung pada umumnya hanya memiliki kurang dari 5 orang yang memiliki keterampilan ukir khas lampung dan khususnya di setiap Kabupaten dan Kecamatan, kerajinan ukir lampung dapat punah walaupun potensi pasar kerajinan ini menghasilkan pendapatan yang tinggi. Perubahan arah peengrajin ukir tidak lagi memiliki kemampuan untuk dapat mengembangkan hasil kreasinya dan lulusan SMK ukir yang tidak melanjutkan pekerjaan sesuai dengan bidangnya sehingga pengrajin dan lulusan SMK ukir lebih memilih kerja sebagai sales, bekerja di panglong kayu dan menjaga toko di daerah perkotaan walaupun pendapatan yang mereka terima rendah. Oleh karena itu, melihat kondisi seperti ini maka UKIR LAMPUNG INDONESIA sebagai kerajinan seni ukir khas Lampung Langkapura Kemiling Bandar Lampung, mempunyai kendala merasa kelangkaan sumber daya manusia untuk melakukan pengukiran dan memasarkannya produknya. Maka peneliti, melakukan kerjasama dengan UKIR LAMPUNG INDONESIA untuk melakukan pelatihan kepada pengukirpengukir khas lampung dan Siswa SMK Negri 5 Sukabumi Bandar lampung. Dimana pengrajin dan lulusan SMK ukir masih sangat kental, selain itu masih banyak pengrajin dan lulusan SMK ukir ini yang tidak memiliki pendapatan. Walaupun memiliki pendapatan tetapi kecil karena kebanyakan dari mereka adalah penjaga toko, sales keliling, dan pegawai panglong kayu dimana tingkat selain lulusan SMK, pendidikan mereka pun rendah.

\section{TARGET DAN LUARAN}

Dengan diajukan proposal pengabdian masyarakat ini maka target yang ingin dicapai dari pelatihan pengrajin ukir dan siswa SMK ukir Sukabumi serta Lulusannya, yaitu :

1. Meningkatkan peran kelembagaan dan permodalan UMKM dalam pengembangan ekonomi lokal yang berdaya saing.

2. Meningkatnya pendapatan rumah tangga kelompok pengrajin ukir.

3. Meningkatnya jumlah kegiatan seni dan budaya.

4. Meningkatnya jumlah wisatawan dan berkunjung ke Lampung untuk melihat kerajinan seni ukir khas lampung dan membeli secara langsung dari tempat produksinya.

5. Berkurangnya jumlah penyandang masalah kesejahteraan sosial (PMKS).

6. Meningkatnya akses dan kualitas prasarana dan sarana terutama untuk pendistribusian produk seni ukir khas lampung menggunakan internet.

Luaran yang ingin dicapai adalah adanya penerus yang memiliki keterampilan dalam melestarikan seni ukir khas lampung pada pengrajin dan lulusan SMK negeri 5 Sukabumi bandarlampung,

UKIR Lampung Indonesia Langkapura Kemiling Bandar Lampung, yang menyebabkan tetap adanya keberlangsungan kerajinan seni ukir dengan terciptanya produk. Kerajinan seni ukir khas lampung.

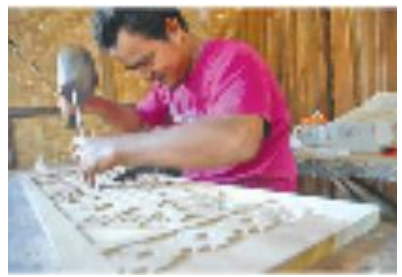

Gambar 1. Proses Pengukiran Motif ukir Khas lampung

Sumber : Majalah_Ekraf_Unik Etnik Ukiran Lampung

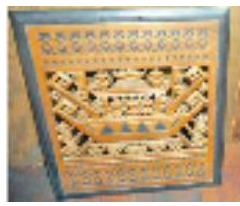

Gambar 2. Contoh Hiasan Dinding Ukiran Lampung

Sumber :

http:/ www.google.com/\#q=ukir+lampung 
Dalam rangka menciptakan posisi yang tepat untuk suatu produk maka produsen maupun pemasar harus mengomunikasikan dan memberikan manfaat-manfaat tertentu yang dibutuhkan pasar sasaran yaitu dengan memilih model dengan posisi kompetitif agar terciptanya pemasok melalui pengembangan daerah produksi kerajianan seni ukir khas lampung dari pelatihan pada kelompok pengrajin dan lulusan SMK ukir Sukabumi Bandar lampung, Lampung model yang dipakai yaitu: (Robert A Burgelman:2004).

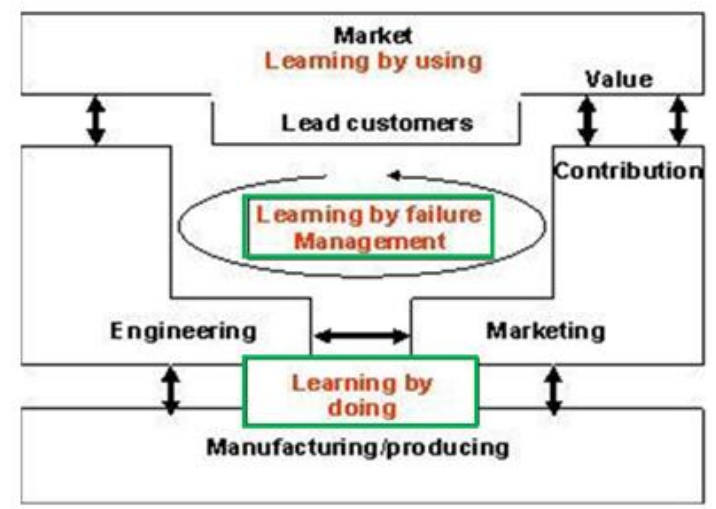

Secara umum, posisi kompetitif dinilai berdasarkan sejumlah dimensi yang berpengaruh terhadap kinerja pasar (market performace) yang memiliki dimensi posisi struktural, posisi strategis, posisi pemasaran/market dan posisi sumberdaya. Dari model ini akan memberikan manfaat dalam menilai dominasi relatif sebuah perusahaan di pasar tertentu dalam posisi kompetitif baik dalam posisi kompetitif baik dalam negeri maupun luar negeri, yang kemudian strategi pemasaran kompetitif dapat dievaluasi dan dirancang.

UKIR Lampung Indonesia Langkapura Kemiling Bandar Lampung, yang menyebabkan tetap adanya keberlangsungan kerajinan seni ukir dengan terciptanya produk. Kerajinan seni ukir khas lampung

\section{METODE PELAKSANAAN}

Adapun langkah yang akan ditempuh dalam kegiatan Pengabdian Masyarakat ini mencakup beberapa tahap berikut ini :

\section{Persiapan}

Dalam tahap persiapan ini ada beberapa hal yang dilakukan oleh tim pelaksana, yakni koordinasi tim pelaksana untuk merencanakan pelaksanaan secara konseptual, operasional, serta pembagian tugas masing-masing anggota, penentuan dan rekruitmen peserta pelatihan, pembuatan instrumen pengabdian masyarakat seperti lembar presensi, angket, lembar kerja, sertifikat, pelatihan dan persiapan konsumsi, publikasi, ijin penggunaan lokasi, dokumentasi, pembuatan design e-commerce dan sebagainya.

\section{Pelaksanaan Pelatihan}

Tahap ini merupakan tahap pelatihan yang diberikan kepada pengrajin ukir dan siswa SMK dan lulusan SMK ukir Sukabumi Bandar Lampung. Pelaksanaan mencakup

\section{a. Penyajian Materi}

Materi yang disajikan terkait yaitu praktek kerja cara membuat motif ukir dan teknik mengukir. Materi disajikan oleh tim pelaksana kerajinan ukir dari UKIR LAMPUNG INDONESIA Langkapura Kemiling

\section{b. Penugasan Praktik}

Para pengrajin ukir, siswa SMK ukir dan Lulusannya diberi tugas praktek. Dalam tahap ini peserta akan ditugaskan untuk membuat suatu produk kerajinan ukir dengan bahan yang telah disediakan oleh tim pelaksana dengan pola sesederhana mungkin agar mudah pengerjaannya. Produk yang telah dibuat kemudian diajarkan cara membuat pola untuk membentuk produk seperti souvenir, hiasan dinding dan seni ukir pada perabot rumah tangga. Tim pengabdian masyarakat akan mendampingi, memandu dan mengarahkan serta memberikan solusi apabila timbul permasalahan selama penugasan praktek.

\section{c. Refleksi dan Penutupan Program Pengabdian Masyarakat}

Di akhir kegiatan peserta dan tim pengabdian akan melakukan refleksi hasil pelatihan dan para peserta juga memberikan evaluasi akan pelatihan ini. Tim juga memberikan pelatihan penggunaan E-commerce untuk dapat memasarkan produk hasil ukir melalui dunia internet. Setelah semua 
kegiatan yang telah direncanakan terlaksana.

\section{Evaluasi Kegiatan}

Evaluasi kegiatan pengabdian masyarakat ini dilakukan dengan beberapa cara, yakni evalusi terhadap proses dan evaluasi terhadap hasil. Evaluasi terhadap proses dilihat dari keseriusan dan ketekunan para peserta dalam mengerjakan tugas praktek dan evaluasi terhadap hasil dinilai dari hasil karya peserta. Hasil prakteknya dinilai dan hal itu menggambarkan keberhasilan materi yang telah disajikan. Selain itu, secara proses juga dicermati kinerja dan kesertaan para peserta agar bisa terjalin kemitraan dalam bidang usaha kerajinan seni ukir lampung.

\section{BAB IV. KELAYAKAN PERGURUAN TINGGI}

Institut Informatika dan Bisnis Darmajaya Bandar Lampung adalah salah satu Perguruan Tinggi Swasta yang menekankan pada jiwa enterpreneurship. Hal ini bisa terlihat dari visi yaitu menjadi perguruan tinggi yang unggul dan berdaya saing berbasis teknologi dan bisnis. Misi adalah melakukan sistem pembelajaran yang kreatif dan adaptif terhadap kemajuan teknologi dan bisnis, mengembangkan penelitian dan pengabdian masyarakat yang inovatif serta relevan dengan kebutuhan stakeholder , menciptakan manajemen pendidikan tinggi yang bermutu dan akuntabel, menciptakan lingkungan pembelajaran dan penelitian yang kondusif dan menghasilkan lulusan yang kompeten dibidangnya dan berwawasan technopreneurship untuk mencapai tujuan dari visi dan misi ini maka Institut Informatika dan Bisnis darmajaya memiliki lembaga pelatihan dan pusat bisnis dimana menaungi pusat pelatihan dan bisnis berupa DLC yaitu pusat bahasa,

DJCTC yaitu pusat pelatihan teknologi dan inkubator bisnis yaitu pusat kegiatan kewirausahaan. Selain itu Institut Informatika dan Bisnis Darmajaya juga bekerjasama dengan perguruan tinggi UTEM Malaysia untuk kegiatan kewirausahaan. Dengan adanya pusat pelatihan dan bsinis di Institut Informatika dan Bisnis Darmajaya maka pelaksanaan pelatihan bagi pengrajin ukir dan siswa lulusan SMK ukir Sukabumi Bandar lampung, pada pelestarian kerajinan seni ukir khas lampung bisa terjalin kemitraan.

Dalam pelaksanaan kegiatan pengabdian masyarakat di bawah naungan LP4M yang sudah dilakukan sejak tahun 2009 sampai sekarang melalui jurusan manajemen Institut Informatika dan Bisnis Darmajaya yaitu program Praktek Kerja Pengabdian Masyarakat dengan tujuan yaitu untuk mengembangkan jiwa enterpreneurship, untuk menggali petensi daerah tujuan guna mengembangkan kreatifitas masyarakat melalui kelompok usaha bersama yang telah dibentuk dengan bekerjasama Institut Informatika dan Bisnis Darmajaya, untuk bahan penelitian mahasiswa dan dosen untuk menjalin kerjasama berkelanjutan bagi LP4M, Ikubator Bisnis, Training Center dengan Pemerintah Provinsi Lampung.

Sasaran dilaksanakannya Praktek Kerja Pengabdian Masyarakat yaitu : terciptanya usaha produktif masyarakat desa dan terbentuknya sistem pelatihan dari IIB Darmajaya melalui Darmajaya Training Center (DJTC) yang bermanfaat bagi kebutuhan masyarakat, terbukanya peluang usaha masyarakat sehingga meningkatkan tingkat kesejahteraan masyarakat desa sasaran dan terciptanya empati dalam diri mahasiswa melalui program interaksi dan sosialisasi terhadap masyarakat dan daerah potensi sasaran.

Melihat kondisi seperti ini maka peneliti dalam naungan Institut Informatika dan Bisnis Darmajaya merasa layak jika dilakukan pelatihan pada pengrajin ukir, siswa SMK negri 5 Sukabumi dan Lulusannya di Provinsi Lampung. Dimana hasil dari kerajinan seni ukir ini dapat dipamerkan dalam kegiatan kerjasama dengan perguruan tinggi UTEM Malaysia sehingga dapat memperluas pangsa pasar seni ukir khas lampung di mancanegara. 


\section{BAB V. HASIL YANG DICAPAI}

\section{KEGIATAN}

Kegiatan Pelatihan Ukir dilaksanakan di dua lokasi yaitu di Sekolah Luar Biasa (SLB) Provinsi Lampung dan SMK negri 5 Sukabumi yang diikuii oleh siswa dan lulusan serta pengrajin ukirDan kemudian yang akan di sampaikan adalah bagaimana menggunakan media internet yaitu e-commerce.

\section{HASIL}

Hasil kegiatan ini diantaranya berupa transfer pengetahuan ke peserta pelatihan yang nantinya diharapkan dapat memanfaatkan pelatihan ini sebagai media pembelajaran dan sekaligus memperdalam pengetahuan peserta ukir.

Adapun kegiatan ini telah dipublikasikann diantaranya melalui media web dan tabloid harian (Koran) http:// www.darmajaya.ac.id/content/view/1 583/ sebagai berikut :

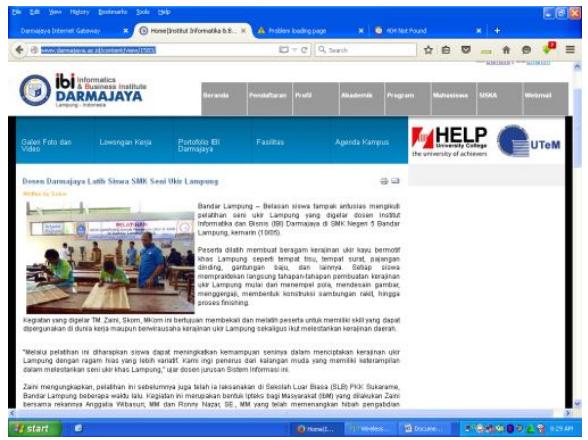

Gambar 3. Kegiatan pelatihan ukir yang dipublikasikan melalui web

Bahan utama yang digunakan sebagai media ukir dalam pelatihan ini adalah Kayu dari bahan jati. Dan menggunakan peralatan seperti pahat, pahat ukir, palu gergaji mesin, mesin bubut dan pelralatn pertukagan lainnya.

Hasil kerajinan ukir ini berupa karya kerajinan diantaranya : ukir pajangan dinding hiasan ukir lampung, gantungan baju, dan rak ukir tempat bumbu (perabot dapur).
Selain itu juga hasil produk ini dapat di promosikan dan dipasarkan melalui media e-commerce dengan media ini kiranya pengrajin yang sudah dilatih dapat memanfaatkan media ini guna lebih memperkenalkan hasil kerajinanannya melalui dunia maya.

Adapun dasar desain untuk pembangunan web e-commerce telah dihasilkan header sebagai tampilan halaman web guna mendukung promosi produk ukir, yaitu :

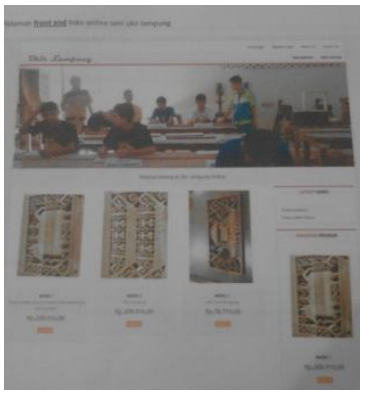

Gambar 4. desain template untuk header halaman e-commerce

Adapun bebrapa kegiatan yang telah berjalan berupa photo yang juga akan digunakan dalam e-commerce diantaranya adalah sebagai berikut:

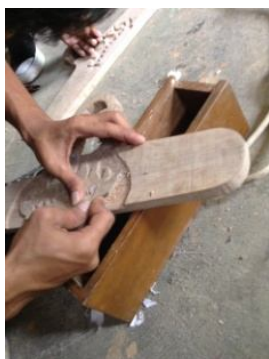

Gambar 5. Proses Pengukiran

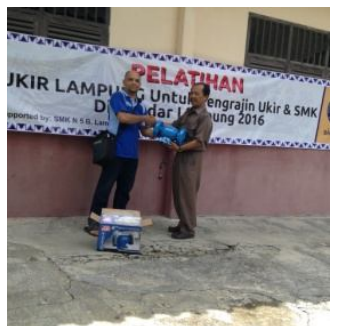

Gambar 6. Penyerahan Bantuan 


\section{BAB VI KESIMPULAN DAN SARAN}

\section{KESIMPULAN}

Berdasarkan hasil diatas maka dapat disimpulkan :

1. Dengan Kegiatan Pelatihan dan $e$ commerce potensi perekonomian dan pemberdayaan masyarakat dapat meningkat dalam kelembagaan dan pemodalan UMKM..

2. Pendapatan rumah tangga kelompok pengrajian dapat meningkat.

3. Meningkatnya jumlah kegiatan seni dan budaya lapung khususnya di bidang ukir khas lampung.

4. Dapat meningkatkan jumlah wisatawan berkunjung ke Lampung untuk melihat dan membeli secara langsung ke produsen.

5. Berkurangnya jumlah penyandang masalah kesejahteraan Sosial )PMKS).

SARAN

Perlunya pemberian modal usaha, kerjasaman dan pembekalan untuk pengrajin guna dapat meningkatkan hasil produksinya, berinovasi dan memasarkannya leih luas lagi.

\section{DAFTAR PUSTAKA}

[1] Robert A. Burgelman. 2004. Strategic Management of Technology and Innovation, Mc Graw Hill.

[2] Pressman, R.S, 2001, "Software Engineering, A Practitioner's Approach", Fifth Edition, McGrawHill Companies, Inc.

[3] EKraf, Tabikpun, September 2010, Unik Etnik Ukiran Lampung.

https://www.google.com/maps/

https://www.google.com/\#q=ukir+lampung

https://www.google.com/\#q=manajemen+pe masaran+ukir+lampung

https://www.google.com/\#q=internet+ecommerce 